\title{
Research on Feed Motion Control Based on Fuzzy PID Short Arc Milling
}

\author{
Yang Yunhui \\ School of mechanical and electrical engineering, Yunnan Open University, Kunming 650223, China \\ yangyunhui@126.com
}

Keywords: Fuzzy PID; short arc milling; feed motion; control.

\begin{abstract}
This paper mainly introduces the feed motion control method based on fuzzy PID short arc milling. The new short arc machining technology has great advantages in dealing with high hardness, high toughness and super strength material, but the control method still needs to be improved. The adaptive control system based on fuzzy PID can solve this problem well. The application of adaptive control system based on fuzzy PID can greatly improve the operation efficiency of short arc milling technology.
\end{abstract}

\section{Introduction}

With the development of science and technology industry of our country, put forward a very high demand on many fields, especially in the field of aviation, military industry and construction industry, they use materials with special strong, for performance requirements of materials there are great differences, in order to meet the special requirements of these special materials, a short arc machining technique model began to appear.

\section{Short arc machining}

Short arc machining is a non-contact processing power, in the process of generating electricity, a special function of the cutter and the workpiece surface, high temperature and high heat so that the workpiece surface rapidly melting, in applying the working fluids, the workpiece surface of molten metal from the workpiece, obtain the size precision and surface roughness. When using short arc machining technology, workpiece is usually used as anode and tool electrode as cathode. Short arc machining technique has great advantage in processing, the effect is very good, the energy consumption is relatively low, although the short arc machining technique is still in the research stage, but it has very broad prospects for development in the processing of hard materials. The relationship between the processing efficiency and the feed system of short arc machining technique is very close, short arc machining is usually in complex environment, many factors such as the duty ratio and the spindle speed will cause the feed movement changes, in this case, if we still use the traditional control method is difficult to to meet the demand of modern intelligent processing standard. In order to solve this problem, we try to use fuzzy PID technology to adjust the feed motion, which can greatly improve the efficiency of short arc machining and reduce the loss of electrode. In the use of short arc machining technique for processing hard material, electrode erosion rate is very low, so we must find a can to ensure uniform and stable feeding mode at low speed, if a short circuit or overload occurs in the circuit, the electrode to be able to quickly return, guaranteed not to cause burns on the workpiece. To ensure the accuracy of processing the material.

\section{Design of automatic control system for short arc machining}

Short arc machining is a non-contact processing method, short arc discharge in the gap is very small, even if the factors will affect the current changes, so the workpiece in the use of short arc machining technique, the servo feed control precision is very high. A servo control system is a 
feedback control system that is used to accurately follow or reprint a certain process. Also known as servo system, in many cases, refers to the servo system is to control the amount of the feedback control system of mechanical displacement or displacement velocity and acceleration, its role is to make the mechanical displacement displacement output accurately follow the input of the feedback control system, servo system structure and other forms of no difference principle. The general servo system has three commonly used control methods, including open loop servo system control mode, closed loop servo system control mode and version closed loop servo system control mode. In this study, we mainly discuss the control method of close loop servo system, the closed-loop servo system driven by the servo motor, the servo motor can collocation various types of speed and position detection device, there are many types of feedback. In closed loop servo system, the detection element can detect the actual location of the moving parts of the machine in real time, and transform the location information of the moving parts of the machine tool into electrical signals, and feedback them to the comparison links.

The comprehensive design of the traditional automatic control system must be based on the precise mathematical model of the controlled object. However, in the actual industrial production, the system is affected by many factors, so it is very difficult to establish an accurate mathematical model. According to the actual output of the controlled object and the working experience of the field operator, fuzzy control system can achieve real-time control of the system without the establishment of a precise mathematical model of the system. The main features of fuzzy control are:

Fuzzy control is a kind of imitation of human thinking and control method based on fuzzy rules, on the basis of field experience of the operator or expert knowledge, uses language control rules, does not depend on the accurate mathematical model of the system, the control mechanism has the advantages of simple design, easy to understand, easy to use, especially suitable for complex systems and fuzzy control object.

The core of fuzzy control system is fuzzy controller, and fuzzy controller is based on microprocessor or computer, so it has the characteristics of computer control system.

The robustness of fuzzy control system is very strong, and the influence of external disturbances and system parameters on the control effect is relatively small, which facilitates the control of system nonlinearity and parameter time-varying of AC servo system. The traditional control method needs to give a very clear mathematical expression, but fuzzy control imitating human's thinking mode, based on fuzzy mathematics, has great difference with traditional control methods, and has a good development prospect [1].

\section{Adaptive control system for short arc machining}

\subsection{Control system model of short arc machining}

The principle of fuzzy adaptive PID controller is the application of basic theory and method of fuzzy mathematics, the conditions of the rules and the operation with the representation of fuzzy sets, and the fuzzy control rules and the related information stored in the computer as a knowledge repository, then the computer according to the actual response of the control system using fuzzy reasoning can be realized automatically on the adjustment of PID parameters, the fuzzy adaptive PID control. The transfer function of the servo control system of short arc milling machine is mainly composed of motor transfer function, $\mathrm{G}(\mathrm{s})=\mathrm{kml} /$ (TmTiS2+Tms +1 ), where Tm refers to the time constant of AC motor, Ti refers to the electromagnetic time constant armature circuit, KML refers to the proportion of the number of lines.

\subsection{Design and algorithm of fuzzy PID controller}

The PID controller parameter tuning difficult limitations, using the basic theory and method of fuzzy mathematics, the conditions of the rules and the operation of the representation of fuzzy sets, fuzzy control rules and the relevant information as the knowledge stored in the knowledge base, according to the actual response of the control system, using fuzzy inference, the PID parameters 
automatically the best tuning to achieve. In the short arc milling system, if the feed speed is greater than the machining speed, the phenomenon of mechanical processing will happen. At this time, the force of the tool electrode will appear flexure. The calculation equation of electrode deflection is: $\mathrm{F} \frac{\partial^{2} \mathrm{y}}{\partial \mathrm{z}^{2}}-\mathrm{EI} \frac{\partial^{4} \mathrm{y}}{\partial \mathrm{z}^{4}}=\mathrm{pS} \frac{\partial^{2} \mathrm{y}}{\partial \mathrm{t}^{2}}+\mathrm{C} \frac{\partial \mathrm{y}}{\partial \mathrm{t}}$, where F refers to the carrying force, E refers to the elastic modulus, I refers to the inertia moment, $\mathrm{S}$ is the cross section area, $\mathrm{C}$ refers to the damping coefficient.

In the short arc milling process, the role of servo control system is very important, because in machining, electrode and workpiece must be kept at a certain interval. Because the workpiece is continuously eroded, the electrode has certain loss, and the gap will continue to expand. If the electrode is not compensated in time, the discharge process will stop because the gap is too large. Conversely, if the clearance is too small, it will cause the arcing burn or short circuit. At that time, the electrode must leave the workpiece quickly, then it will be readjusted to the appropriate discharge gap after the short circuit is eliminated. Because the gap in the discharge gap is very small, the suitable discharge gap must be completed by the automatic feed adjustment system (2). Fuzzy adaptive PID controller is mainly composed of two main components of PID controller and fuzzy inference device. The advantage of fuzzy PID in controlling feed motion is that it can get better robust performance without mathematical models. The main feature of the fuzzy adaptive PID controller is that it can use the conventional PID adjustment to achieve a satisfactory adjustment effect. Structure diagram of fuzzy adaptive PID control system as shown in Figure 1.

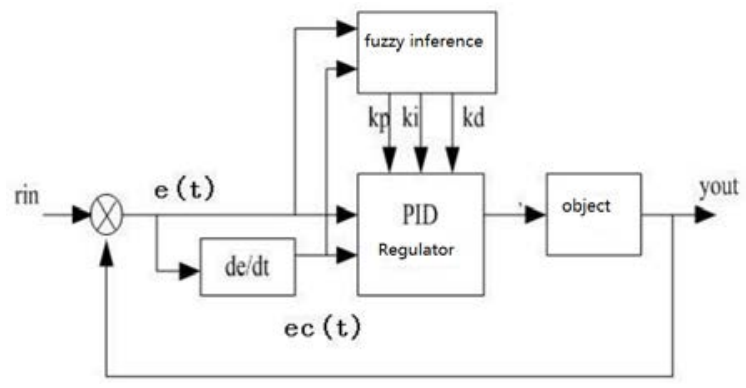

Figure 1. Structure diagram of fuzzy adaptive PID control system

The control equations of the fuzzy PID controller are: e $(T)=r(T)-y(T)$. Time domain controller output equation: $u(t)=K p e(t)+K i \int e(t) d t+K d \frac{d e(t)}{d t}$. The $E(T)$ refers to the deviation, and $\frac{\mathrm{de}(\mathrm{t})}{\mathrm{dt}}=\mathrm{ec}$ refers to the deviation rate.

According to the expert's experience [3], we can draw a fuzzy rule table for each parameter, as shown in Table 1.

Table 1. $\triangle \mathrm{Kp} 、 \triangle \mathrm{K} 1 、 \triangle \mathrm{KdFuzzy}$ rule control table

\begin{tabular}{|c|c|c|c|c|c|c|c|c|}
\hline \multirow{2}{*}{\multicolumn{2}{|c|}{$\Delta K_{\mathrm{p}} / \Delta K_{\mathrm{i}} / \Delta K_{\mathrm{d}}$}} & \multicolumn{7}{|c|}{$\mathrm{EC}$} \\
\hline & & \multirow{2}{*}{$\begin{array}{c}\mathrm{NB} \\
\mathrm{PB} / \mathrm{NB} / \mathrm{PS}\end{array}$} & \multirow{2}{*}{$\begin{array}{c}\mathrm{NM} \\
\mathrm{PM} / \mathrm{PB} / \mathrm{PS}\end{array}$} & \multirow{2}{*}{$\frac{\mathrm{NS}}{\mathrm{Z0} / \mathrm{NM} / \mathrm{NS}}$} & \multirow{2}{*}{$\frac{\mathrm{ZO}}{\mathrm{PM} / \mathrm{NM} / \mathrm{NM}}$} & \multirow{2}{*}{$\frac{\mathrm{PS}}{\mathrm{PM} / \mathrm{NS} / \mathrm{NM}}$} & \multirow{2}{*}{$\begin{array}{c}\mathrm{PM} \\
\mathrm{NB} / \mathrm{ZO} / \mathrm{NB}\end{array}$} & \multirow{2}{*}{$\begin{array}{c}\mathrm{PB} \\
\mathrm{NS} / \mathrm{ZO} / \mathrm{PS}\end{array}$} \\
\hline \multirow{7}{*}{$\mathrm{E}$} & NB & & & & & & & \\
\hline & NM & $\mathrm{PB} / \mathrm{NB} / \mathrm{PS}$ & $\mathrm{PB} / \mathrm{PB} / \mathrm{NS}$ & $\mathrm{PM} / \mathrm{NM} / \mathrm{NB}$ & $\mathrm{PS} / \mathrm{NS} / \mathrm{NM}$ & $\mathrm{PS} / \mathrm{NS} / \mathrm{NM}$ & $\mathrm{ZO} / \mathrm{ZO} / \mathrm{NS}$ & $\mathrm{ZO} / \mathrm{ZO} / \mathrm{ZO}$ \\
\hline & NS & $\mathrm{PB} / \mathrm{NS} / \mathrm{ZO}$ & $\mathrm{PM} / \mathrm{NB} / \mathrm{NS}$ & $\mathrm{PS} / \mathrm{NS} / \mathrm{NM}$ & $\mathrm{ZO} / \mathrm{NS} / \mathrm{NS}$ & $\mathrm{ZO} / \mathrm{ZO} / \mathrm{NS}$ & NS/PS/NS & $\mathrm{NS} / \mathrm{PS} / \mathrm{ZO}$ \\
\hline & $\mathrm{ZO}$ & $\mathrm{PM} / \mathrm{NM} / \mathrm{ZO}$ & $\mathrm{PS} / \mathrm{NB} / \mathrm{NS}$ & $\mathrm{PS} / \mathrm{NS} / \mathrm{NS}$ & $\mathrm{ZO} / \mathrm{ZO} / \mathrm{ZO}$ & $\mathrm{ZO} / \mathrm{ZO} / \mathrm{ZO}$ & NS/PS/NS & NM/PM/ZO \\
\hline & PS & $\mathrm{PS} / \mathrm{NM} / \mathrm{ZO}$ & $\mathrm{PS} / \mathrm{NS} / \mathrm{ZO}$ & $\mathrm{zo} / \mathrm{ZO} / \mathrm{ZO}$ & $\mathrm{NM} / \mathrm{ZO} / \mathrm{NM}$ & NS/PS/NM & NM/PM/ZO & $\mathrm{NB} / \mathrm{PM} / \mathrm{ZO}$ \\
\hline & PM & $\mathrm{PS} / \mathrm{ZO} / \mathrm{NB}$ & $\mathrm{PS} / \mathrm{ZO} / \mathrm{NS}$ & $\mathrm{PM} / \mathrm{ZO} / \mathrm{ZO}$ & Z0/PS/PM & NS/PM/PM & NM/PB/PS & $\mathrm{NB} / \mathrm{PB} /[\mathrm{B}$ \\
\hline & PB & $\mathrm{ZO} / \mathrm{ZO} / \mathrm{PB}$ & $\mathrm{ZO} / \mathrm{ZO} / \mathrm{PM}$ & NS/PS/PM & NS/PS/PS & NM/PM/PS & $\mathrm{NB} / \mathrm{PB} / \mathrm{PB}$ & $\mathrm{NB} / \mathrm{PB} / \mathrm{PB}$ \\
\hline
\end{tabular}




\section{Summary}

After we edit the control rules, the rules of language viewer open, variable control surfaces were observed (Fig. 2), we can find through the observation of the whole surface is very smooth, and no 90 degree bump phenomenon, which shows that the fuzzy PID control system can meet the demand of stability control for short arc milling feed movement.

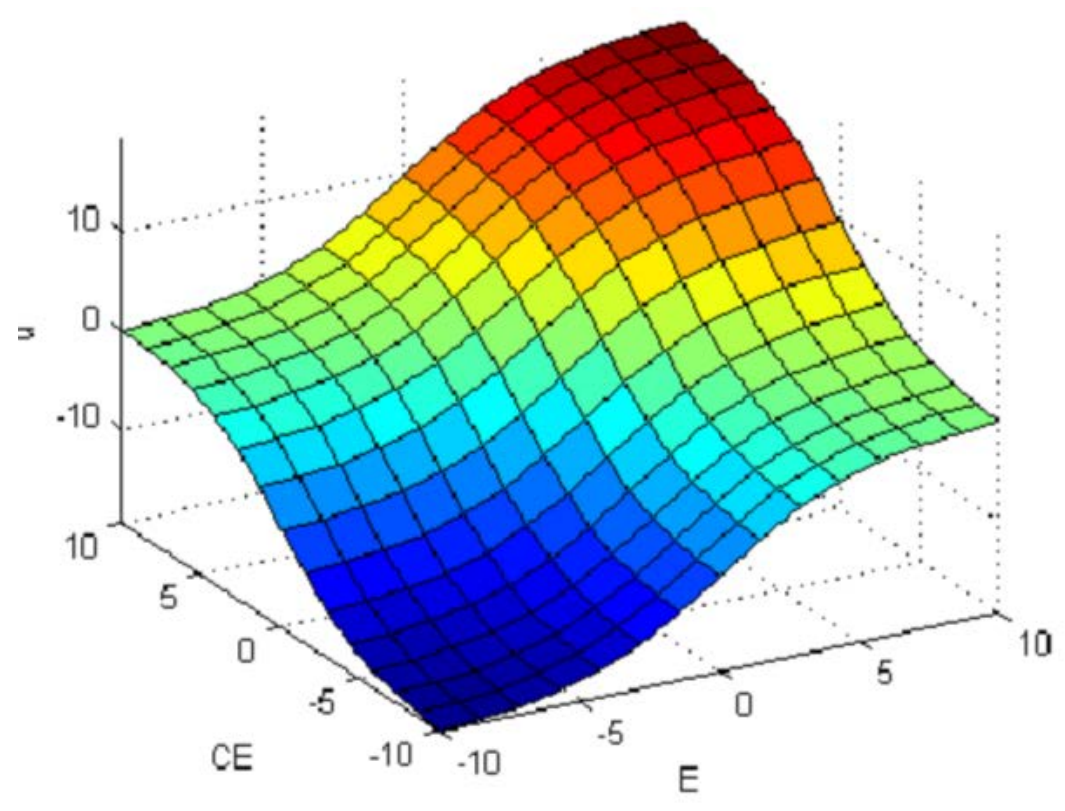

Figure $2 . \triangle \mathrm{Kp} 、 \triangle \mathrm{K} 1 、 \triangle \mathrm{KdControl} \mathrm{surface} \mathrm{map}$

\section{References}

[1] Liu Yaqi, Zhou Jianping, Xu Yan. Based on fuzzy PID short arc milling machining feed motion control [J]. manufacturing technology and machine tools, 2016 (10): 28-29.

[2] Wang Shuyan, Shi Yu, Feng Zhongxu. Research on [J]. mechanical science and technology based on the control method of fuzzy PID controller, 2016, 30 (1): 166-167.

[3] Lu Weijia, high East, Zhang Nanfeng, and so on. Application of fuzzy control technology to automatic tracking of welds of arc welding [J]. manufacturing technology and machine tool, 2017 (7): 53-54. 